\title{
Apoptosis Induced by HIV-1 Infection of the Central Nervous System
}

\author{
Bin Shi, ${ }^{\star \ddagger}$ Umberto De Girolami, ${ }^{\ddagger}$ Jianglin He, ${ }^{\star \ddagger}$ Shu Wang, ${ }^{\star \ddagger}$ Alfredo Lorenzo, ${ }^{\| \uparrow}$ Jorge Busciglio,,$\|$ and Dana Gabuzda ${ }^{\star \|}$ \\ *Division of Human Retrovirology, Dana-Farber Cancer Institute, Boston, Massachusetts 02115; ${ }^{\S}$ Department of Pathology, Brigham and

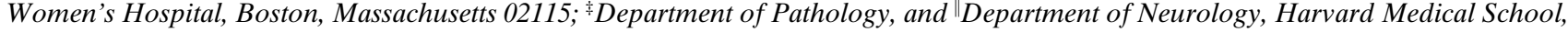 \\ Boston, Massachusetts 02115; and "IDepartment of Neurology, Children's Hospital Medical Center, Boston, Masssachusetts 02115
}

\begin{abstract}
Apoptosis plays a role in AIDS pathogenesis in the immune system, but its role in HIV-1-induced neurological disease is unknown. In this study, we examine apoptosis induced by HIV-1 infection of the central nervous system (CNS) in an in vitro model and in brain tissue from AIDS patients. HIV-1 infection of primary brain cultures induced apoptosis in neurons and astrocytes in vitro as determined by terminal deoxynucleotidyl transferase-mediated dUTP nick end labeling (TUNEL) and propidium iodide staining and by electron microscopy. Apoptosis was not significantly induced until 1-2 wk after the time of peak virus production, suggesting induction by soluble factors rather than by direct viral infection. Apoptosis of neurons and astrocytes was also detected in brain tissue from 10/11 AIDS patients, including 5/5 patients with HIV-1 dementia and 4/5 nondemented patients. In addition, endothelial cell apoptosis was frequently detected in the brain of AIDS patients and was confirmed by electron microscopy. Most of the apoptotic cells were not localized adjacent to HIV-1-infected cells, providing further evidence for induction by soluble factors. In six non-AIDS control patients with normal brain, apoptotic cells were absent or limited to rare astrocytes. However, TUNEL-positive neurons and astrocytes were frequently detected in seven patients with Alzheimer's disease or abundant senile plaques. These studies suggest that apoptosis is a mechanism of CNS injury in AIDS which is likely to be induced by soluble factors. The apoptosis of endothelial cells in the CNS raises the possibility that some of these factors may be blood-derived. (J. Clin. Invest. 1996. 98:1979-1990.) Key words: AIDS • HIV • encephalitis • apoptosis • dementia
\end{abstract}

\section{Introduction}

The human immunodeficiency virus type 1 (HIV-1) infects the brain in the majority of adults and children with AIDS, causing a spectrum of neurological and psychiatric symptoms in up to $20 \%$ of AIDS patients (1-4). These range from mild cognitive

\footnotetext{
Address correspondence to Dana Gabuzda, Dana-Farber Cancer Institute, JF 712, 44 Binney Street, Boston, MA 02115. Phone: 617-6322154; FAX: 617-632-3113; E-mail: dana@gabuzda@dfci.harvard.edu Received for publication 8 February 1996 and accepted in revised form 4 September 1996.
}

J. Clin. Invest.

(C) The American Society for Clinical Investigation, Inc. 0021-9738/96/11/1979/12 \$2.00

Volume 98, Number 9, November 1996, 1979-1990 impairment to HIV-1 dementia, a progressive dementing disorder which is frequently accompanied by behavioral and motor abnormalities (5). The major target cells for HIV-1 infection of the central nervous system $(\mathrm{CNS})^{1}$ are macrophages and microglia (1, 6-9). Astrocytes and endothelial cells may also harbor a low level of infection $(8,9,10-13)$. The neuropathology of HIV-1 infection includes brain atrophy, demyelination, reactive astrocytosis, microglial nodules, multinucleated giant cells, and evidence of abnormal blood-brain-barrier permeability $(3-5,14-18)$. Neuronal loss, dendritic pathology, and decreased synaptic density have also been documented (1922). Affected brain regions include the basal ganglia, subcortical white matter, and cerebral cortex $(1,4,14,15)$.

HIV-1 infection of the CNS occurs in asymptomatic HIVseropositive individuals (23). However, most HIV-infected individuals do not develop cognitive symptoms until many years later after the onset of full-blown AIDS. The initial trigger(s) which causes the emergence of clinical dementia in some patients is unknown. Neurons do not appear to be infected with HIV-1, indicating that neuronal cell death is likely to be caused by indirect mechanisms (24). Several factors have been proposed to mediate HIV-1-induced neuronal injury. These include soluble forms of the HIV-1 gp120 and Tat proteins, which are toxic to neurons in vitro, and potentially neurotoxic factors secreted by HIV-1-infected macrophages and microglia, such as TNF- $\alpha$, platelet activating factor, arachidonic acid metabolites, free radicals, nitric oxide, and excitatory amino acids $(2,4,25-28)$. The mechanisms of HIV-1-induced brain injury are likely to be complex, probably involving more than one of these potentially neurotoxic factors and possibly other yet unknown factors.

Apoptosis plays a role in AIDS pathogenesis in the immune system (29), but its role in HIV-1 dementia is unknown. Recent studies of autopsy brain tissue from AIDS patients have demonstrated apoptosis of neurons, astrocytes, and possibly other CNS cell types (30-32). Neuronal apoptosis occurs during normal CNS development, but in the adult brain is only associated with pathological conditions such as stroke and Alzheimer's disease.

In this study, we investigate the role of apoptosis in HIV-1induced neurological disease. We demonstrate that HIV-1 infection of primary brain cultures induces apoptosis of neurons and astrocytes in vitro. These findings are confirmed in brain tissue from AIDS patients. Additionally, our in vivo studies demonstrate endothelial cell apoptosis in the brain of AIDS patients. Our studies provide in vitro and in vivo evidence that

1. Abbreviations used in this paper: CNS, central nervous system; GFAP, glial fibrillary acidic protein; MAP-2, microtubule-associated protein-2, TUNEL, terminal deoxynucleotidyl transferase-mediated dUTP nick end labeling. 
the apoptotic stimuli are likely to be soluble factors rather than direct viral infection. Thus, apoptosis is a likely cause of CNS injury leading to cognitive dysfunction in AIDS patients. The in vitro model for HIV-1-induced neuronal apoptosis described in this study may provide a novel opportunity to test potential neuroprotective agents.

\section{Methods}

Reagents. Reagents were obtained from the following sources: HIV-1 p24 ELISA (DuPont-NEN, Boston, MA); Cell Death Detection ELISA, mouse anti-glial fibrillary acidic protein (GFAP), and proteinase K (Boehringer Mannheim Biochemicals, Indianapolis, IN); Apoptag kit (Oncor, Gaithersburg, MD); mouse anti-microtubuleassociated protein (MAP-2), rabbit anti-GFAP, mouse anti-fibronectin, goat anti-mouse conjugated to FITC, and goat anti-rabbit conjugated to rhodamine (Sigma Chemical Co., St. Louis, MO); mouse anti-CD68 (EBM 11), and rabbit anti-Tau (Dako Corp., Carpinteria, CA); USA Ultra Streptavidin alkaline phosphatase detection system, Tissue Unmasking Fluid, mouse anti-neurofilament, mouse antiGFAP, and mouse anti-factor VIII (Signet Laboratories, Dedham, MA); rabbit anti-HIV-1 p24 (American BioTechnologies, Cambridge, MA); rabbit anti-Nef (E. Zazopoulos, Boston, MA) (33); metal enhanced diaminobenzidine (DAB) substrate kit (Pierce Chemical Co., Rockford, IL); HIV-1 89.6 (NIH AIDS Research and Reference Reagent Program, Rockville, MD) (34); and HIV-1 YU2.C (B. Hahn, G. Shaw, and S. Ghosh, Birmingham, AL) (35).

$H I V-1$ infection of human fetal brain cultures. Human fetal brain tissue was obtained from 13 to 18 wk gestation abortions performed at Brigham and Women's Hospital. The approved protocol for tissue procurement was in compliance with institutional and federal regulations. Human fetal brain cultures were prepared as previously described (36). Briefly, the tissues were minced and incubated briefly with $0.25 \%$ trypsin, dissociated by trituration, extensively washed, and cultured on poly-lysine-coated glass coverslips in DME supplemented with $10 \%$ calf serum, penicillin, streptomycin, and L-glutamine in a humidified $5 \% \mathrm{CO}_{2}$ atmosphere. Cultures at $10-20 \mathrm{~d}$ after plating were infected by incubation with HIV-1 virus stock $(100,000$ reverse transcriptase units) or mock infected with the same volume of control supernatant for $16 \mathrm{~h}$ at $37^{\circ} \mathrm{C}$ and washed twice before addition of fresh medium. Virus stocks were prepared by filtration $(0.45 \mu \mathrm{M})$ of clarified supernatants from infected CEM $\times 174$ cell cultures (34) or from 293 cells transfected as described (35) and stored at $-70^{\circ} \mathrm{C}$. Control supernatants from uninfected CEMx174 or 293 cell cultures were similarly prepared and used for mock infections. A 50\% medium change was performed every 4-7 d. Productive HIV-1 infection was monitored by p24 ELISA or reverse transcriptase assay of culture supernatants. For immunohistochemical staining, cultures were fixed in $4 \%$ paraformaldehyde in phosphatebuffered saline (PBS) for $30 \mathrm{~min}$, washed, and stored in PBS at $4^{\circ} \mathrm{C}$.

Brain tissue. Autopsy brain tissue was obtained from Brigham and Women's and New England Deaconess Hospitals. Postmortem tissue was fixed in formalin and embedded in paraffin for routine histology. Patients with opportunistic CNS infections, focal CNS lesions, or anoxic/ischemic injury were excluded.

HIV-1 p24 ELISA and reverse transcriptase assays. For p24 ELISA, culture supernatants were clarified by centrifugation, adjusted to $0.5 \%$ Triton X-100, and stored at $-70^{\circ} \mathrm{C}$. HIV-1 p 24 ELISA was performed according to the manufacturer's protocol (DuPont-NEN). Reverse transcriptase assays were performed on virion pellets obtained from clarified culture supernatants as described (37).

Detection of histone-associated DNA fragments by ELISA. A sensitive ELISA assay which detects cytoplasmic histone-associated DNA fragments was performed according to the manufacturer's protocol (Cell Death Detection ELISA; Boehringer Mannheim Biochemicals). Cultured cells were harvested by incubation with $0.5 \mathrm{mM}$ EDTA in PBS for $5 \mathrm{~min}$ at room temperature, washed extensively, and pelleted prior to lysis and isolation of the postnuclear cytosolic fraction.

Detection and quantitation of apoptotic nuclei by staining with DNA-binding fluorescent dyes. Apoptotic nuclear morphology was detected by staining with $10 \mu \mathrm{g} / \mathrm{ml}$ propidium iodide or $1 \mu \mathrm{g} / \mathrm{ml}$ Hoechst 33342 for $10 \mathrm{~min}$ at $37^{\circ} \mathrm{C}$. For cultured cells, cells were harvested by incubation with $0.5 \mathrm{mM}$ EDTA in PBS as described above, washed extensively, and fixed in $4 \%$ paraformaldehyde prior to propidium iodide or Hoechst staining. For paraffin sections, slides were deparaffinized in xylenes, rehydrated in graded ethanols, and washed in PBS prior to propidium iodide staining. Stained nuclei were visualized by fluorescence microscopy using a rhodamine or Hoechst wavelength filter. The percentage of apoptotic cells was determined by counting the number of nuclei with morphologic features characteristic of apoptosis (chromatin condensation and nuclear fragmentation) in 300 cells using a $20 \times$ objective.

Terminal deoxynucleotidyl transferase-mediated dUTP nick end labeling (TUNEL) staining. Fragmented DNA was detected in situ by the TUNEL method (38) using a commercially available kit according to the manufacturer's protocol (Apoptag, Oncor) followed by metal-enhanced DAB color development (Pierce Chemical Co.). For studies on cultured cells, cells were grown on poly-lysine-coated coverslips and fixed in 4\% paraformaldehyde in PBS-sucrose. For studies on paraffin-embedded tissue sections, slides were deparaffinized, rehydrated in graded ethanols, pretreated with $20 \mu \mathrm{g} / \mathrm{ml}$ proteinase $\mathrm{K}$ for $15 \mathrm{~min}$ at room temperature, and washed prior to TUNEL staining. After TUNEL staining, sections were lightly counterstained with cresyl violet or methyl green.

Quantitation of TUNEL staining. For studies on cultured cells, the percentage of TUNEL-positive cells was quantitated by counting cells in 20 random microscope fields using a $20 \times$ objective. For studies on paraffin sections, a semiquantitative scale was used to estimate the degree of TUNEL staining in tissue sections counterstained with cresyl violet or methyl green to distinguish TUNEL-positive and -negative cells. The entire tissue section was reviewed by two of the authors (D.G. and U.D.) and the extent of TUNEL staining was estimated and scored as follows: $0=$ negative; $1+=$ rare positive cells; $2+=$ up to 20 positive cells; $3+=>20$ positive cells.

Immunohistochemistry combined with TUNEL staining. TUNEL staining was performed as described above. For cultured cells, immunofluorescence staining was performed after TUNEL staining. The primary antibodies were added overnight at $4^{\circ} \mathrm{C}$ (mouse anti-MAP-2, -GFAP, or -CD68) or for $90 \mathrm{~min}$ at $37^{\circ} \mathrm{C}$ (rabbit anti-Tau, -GFAP, -HIV-1 P24 or -HIV-1 Nef) and secondary antibodies were added for 30 to $60 \mathrm{~min}$ at $37^{\circ} \mathrm{C}$. The coverslips were then washed and mounted for immunofluorescence microscopy. For paraffin sections, immunohistochemical staining was performed after TUNEL staining and subsequent pre-treatment of the slides with Tissue Unmasking Fluid (Signet Laboratories) for $10 \mathrm{~min}$ at $90^{\circ} \mathrm{C}$. The primary antibodies (anti-neurofilament, -GFAP, -Factor VIII, -HIV-1 p24 or -HIV-1 Nef) were added for $30 \mathrm{~min}$ at room temperature and detected using streptavidin alkaline-phosphatase and Fast Red color development according to the manufacturer's protocol USA-AIk Phos detection system (Signet Laboratories).

Electron microscopy. Cultured cells were fixed in $4 \%$ paraformaldehyde as described for TUNEL staining and then fixed overnight in $1.5 \%$ glutaraldehyde in $0.1 \mathrm{M}$ cacodylate buffer $\mathrm{pH} 7.4$ with $0.1 \%$ calcium chloride, postfixed with $1 \% \mathrm{OsO}_{4}$, dehydrated, and embedded into epon. Paraffin sections of autopsy brain tissue were deparaffinized, rehydrated, and stained by the TUNEL method as described above prior to fixation in glutaraldehyde, postfixation in $\mathrm{OsO}_{4}$, and embedding into epon on glass slides as described for cultured cells. The slides were then placed into liquid nitrogen to separate the embedded tissue from the slide prior to cutting ultrathin sections. Sections were contrasted with uranyl acetate and lead citrate and examined by transmission electron microscopy.

Statistical analysis. Data were analyzed by the Student's $t$ test and are presented as the mean \pm SEM or mean \pm SD. 

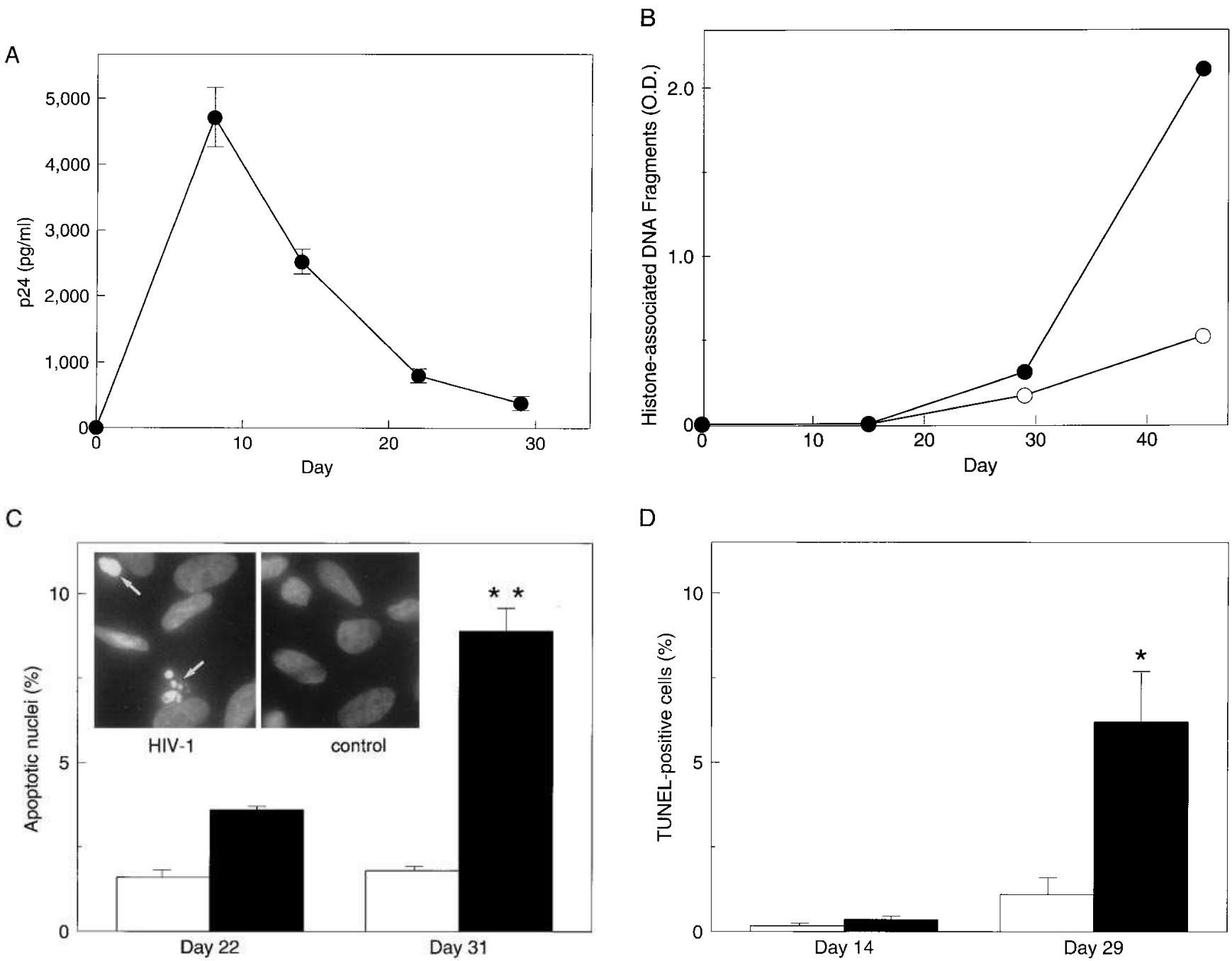

D
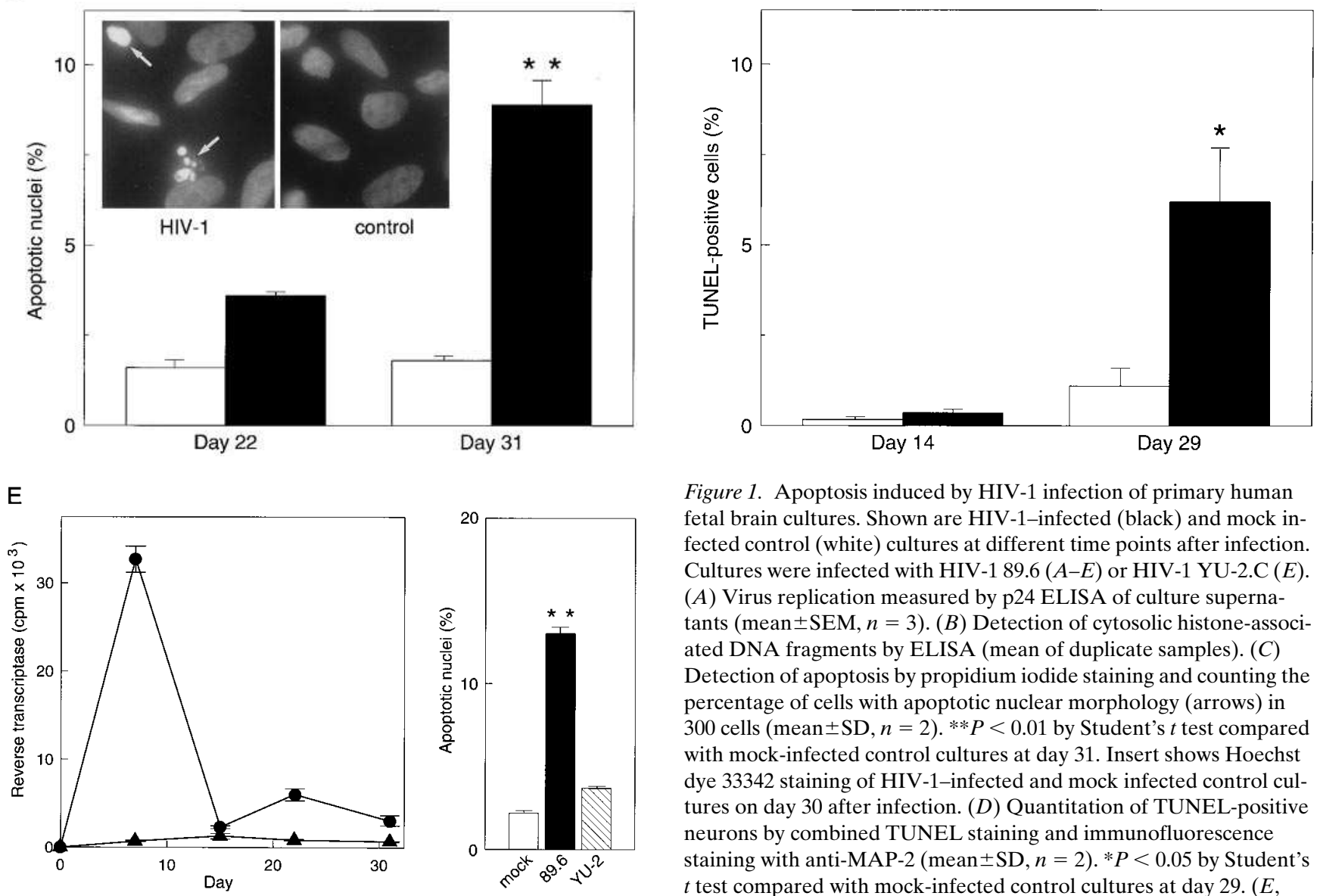

Figure 1. Apoptosis induced by HIV-1 infection of primary human fetal brain cultures. Shown are HIV-1-infected (black) and mock infected control (white) cultures at different time points after infection. Cultures were infected with HIV-1 $89.6(A-E)$ or HIV-1 YU-2.C $(E)$. $(A)$ Virus replication measured by p24 ELISA of culture supernatants (mean \pm SEM, $n=3$ ). (B) Detection of cytosolic histone-associated DNA fragments by ELISA (mean of duplicate samples). (C) Detection of apoptosis by propidium iodide staining and counting the percentage of cells with apoptotic nuclear morphology (arrows) in 300 cells (mean $\pm \mathrm{SD}, n=2$ ). $* * P<0.01$ by Student's $t$ test compared with mock-infected control cultures at day 31. Insert shows Hoechst dye 33342 staining of HIV-1-infected and mock infected control cultures on day 30 after infection. (D) Quantitation of TUNEL-positive neurons by combined TUNEL staining and immunofluorescence staining with anti-MAP-2 (mean $\pm \mathrm{SD}, n=2) . * P<0.05$ by Student's $t$ test compared with mock-infected control cultures at day 29. ( $E$, left) Replication of HIV-1 89.6 (closed circles) and YU-2.C (closed triangles) measured by $\mathrm{RT}$ assay of $0.5 \mathrm{ml}$ of culture supernatant $($ mean $\pm \mathrm{SD}, n=2)$. $(E$, right $)$ Detection of apoptosis by propidium iodide staining as in $C$ (mean $\pm \mathrm{SD}, n=2)$. **P $P 0.01$ by Student's $t$ test compared with mock-infected control cultures at day 29. Results are representative of at least three independent experiments.

\section{Results}

$H I V-1$ infection induces neuronal and astrocyte apoptosis in vitro. Primary human fetal brain cultures were used to determine the effects of HIV-1 infection on primary human neurons. The preparation and maintenance of these cultures has been previously described (36). These cultures contain a mixture of astrocytes (70-90\%), neurons (10-30\%), microglial cells $(1-5 \%)$, and fibroblasts $(1-5 \%)$ as determined by immunofluorescence staining with cell-specific markers. The cultures were infected with HIV-1 89.6, a syncytium-inducing macrophagetropic isolate (34), and productive virus infection 
was monitored by p24 ELISA of the culture supernatants (Fig. 1 A). Productive infection was detected at 7-29 d after the initiation of infection, reaching peak levels between days 7 and 21 (Fig. $1 A$ and not shown). Double immunofluorescence staining with the macrophage/microglia marker anti-CD68 and anti-HIV-1 p24 demonstrated that macrophages and microglial cells were the only productively infected cell type (not shown), consistent with previous studies $(39,40)$.

To determine whether HIV-1 infection of primary brain cultures induces apoptosis, the cultures were infected with HIV-1 and harvested at different time points after infection. Apoptosis was compared in HIV-1-infected and mock infected control cultures (Fig. 1, $B-E$ ). An ELISA assay was used to detect the release of histone-associated DNA fragments into the cytoplasmic fraction in apoptotic cells. By this method, apoptosis induced by infection with HIV-1 89.6 was detected at days 29 and 45 after infection, but not at day 15 (Fig. $1 \mathrm{~B}$ ). The induction of apoptosis in HIV-1-infected cultures was confirmed by propidium iodide or Hoechst 33342 staining and counting the percentage of cells with apoptotic nuclear morphology (Fig. $1 C)(P<0.01$ by student's $t$ test).

To detect apoptosis in HIV-1-infected primary brain cultures in situ, TUNEL staining was performed in combination with immunohistochemical staining using cell-specific markers. In initial experiments, the TUNEL staining method was validated with COS- 1 cells. Apoptosis was induced in COS-1 cell cultures by treatment with $1 \mu \mathrm{M}$ staurosporine for $16 \mathrm{~h}$, conditions which produced an apoptotic DNA ladder and apoptotic nuclear morphology, as detected by staining with propidium iodide. Staurosporine-treated cells were TUNEL-positive, while untreated control cells were negative (not shown). Fixed COS-1 cells treated with DNase were also used as a positive control. Staining in the absence of the terminal deoxynucleotidyl transferase enzyme was used as a negative control. The specificity of TUNEL staining was confirmed by staining with propidium iodide, which confirmed a similar percentage of cells with apoptotic nuclear morphology (Figs. 1, $C$ and $D$ and not shown), and by electron microscopy (see Fig. 3 ).

To determine whether HIV-1 infection of primary brain cultures induces apoptosis of neurons, combined TUNEL staining and immunofluorescence staining with the neuronspecific marker anti-MAP-2 was performed on days 14 and 29 after initiation of infection with HIV-1 89.6 (Figs. $1 D$ and 2). Quantitation of TUNEL-positive cells which were double stained with anti-MAP-2 demonstrated that neuronal apoptosis was significantly induced by HIV-1 infection on day 29 after infection $(P<0.05$ by Student's $t$ test), but not on day 14 (Fig. $1 D)$. The induction of neuronal apoptosis in HIV-1-infected cultures was associated with degeneration of neuritic processes and an overall reduction in MAP-2 staining (Fig. 2 B). In addi-
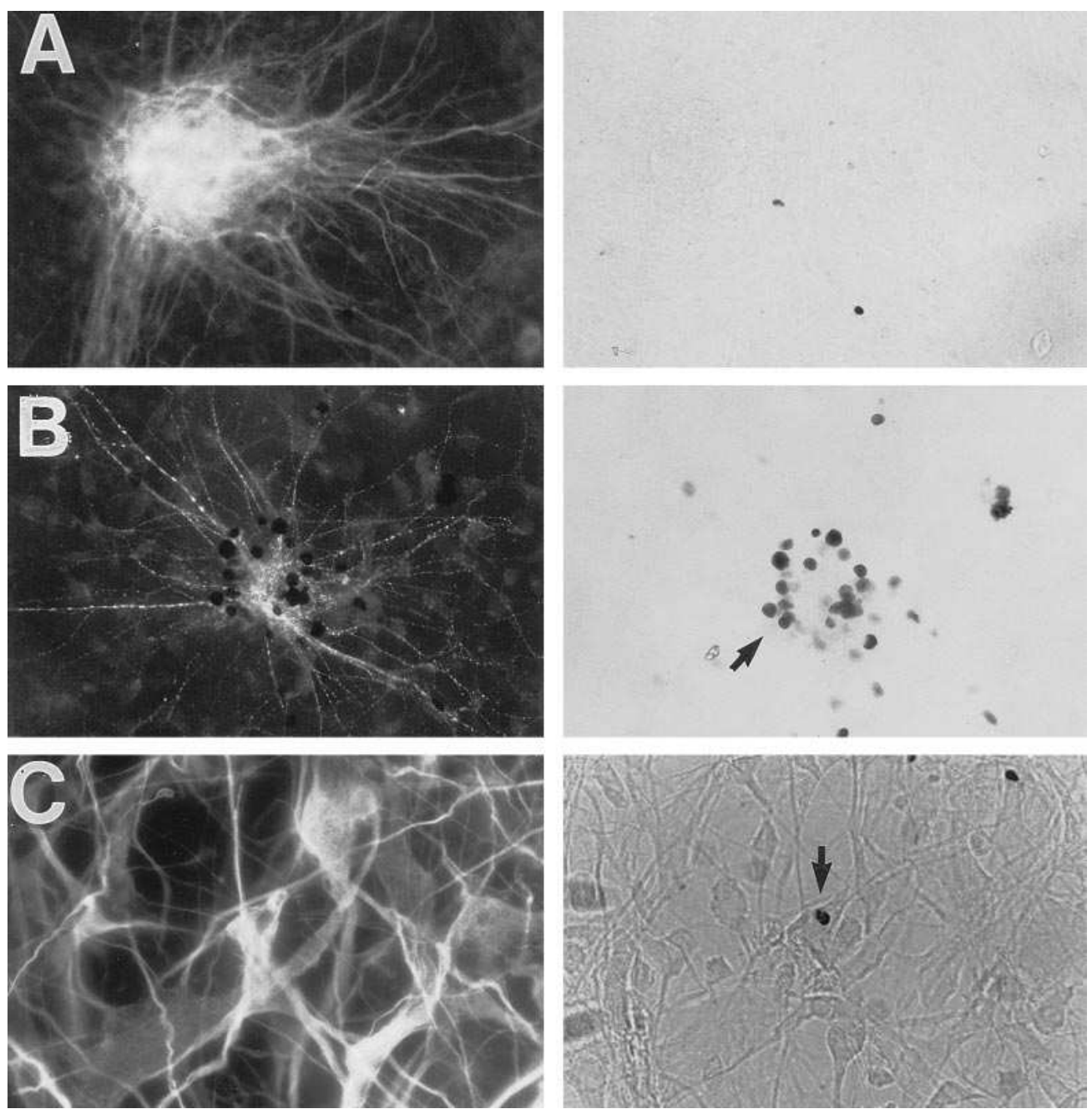

Figure 2. Apoptosis of neurons and astrocytes in HIV-1-infected primary human fetal brain cultures. Combined TUNEL (right panels) and immunofluorescence (left panels) staining of mock infected control $(A)$ and HIV-1infected $(B$ and $C$ ) cultures. Immunofluorescence staining was performed with anti-MAP-2 ( $A$ and $B$ ) or anti-GFAP $(C)$. Apoptotic neurons and astrocytes in HIV-1-infected cultures (arrows). Cultures were fixed on day 29 after infection with HIV-1 89.6. $A$ and $B$, $\times 580 ; C, \times 900$. 
tion, combined TUNEL and immunofluorescence staining with anti-GFAP demonstrated TUNEL-positive astrocytes in HIV-1-infected cultures (Fig. 2 C). Quantitative analysis showed that neuronal apoptosis was induced by 20 -fold in HIV-1-infected cultures relative to mock infected controls, while astrocyte apoptosis was induced by 3 -fold. In the HIV-1infected cultures, $40 \%$ of the TUNEL-positive cells were neurons and $30 \%$ were astrocytes. The remaining TUNELpositive cells were not labeled with either anti-MAP-2 or anti-GFAP, most likely representing cells in the late stages of apoptotic degeneration. Electron microscopy demonstrated ultrastructural features characteristic of apoptosis in HIV-1infected cultures and confirmed apoptotic nuclear morphology in TUNEL-positive cells (Fig. 3).

The preceding experiments demonstrate that infection of primary brain cultures by HIV-1 89.6 induces apoptosis in neurons and astrocytes in vitro. To determine whether this phenotype is due to HIV-1 replication, the induction of apoptosis by this isolate was compared to that of another HIV-1 isolate which replicates inefficiently in this cell culture system (Fig. 1 E). HIV-1 YU-2.C is a derivative of YU-2, a non-syncytiuminducing macrophagetropic isolate which was cloned directly from human brain tissue (35), in which the $v p u$ open reading frame was restored. Primary brain cultures were infected with equivalent amounts of HIV-1 89.6 or YU-2.C and virus replication was monitored. HIV-1 89.6 replicated to high levels, but the replication of HIV-1 YU-2.C was very inefficient in this cell culture system (Fig. $1 \mathrm{E}$, left). The induction of apoptosis by HIV-1 infection was quantitated by propidium iodide staining and counting the percentage of cells with apoptotic nuclear morphology (Fig. $1 \mathrm{E}$, right). Apoptosis was significantly induced by infection with HIV-1 89.6 on day 29 after infection $(P<0.01$ by Student's $t$ test). In contrast, infection with HIV-1 YU-2.C caused only a minor increase in apoptosis which was not statistically significant relative to mock infected control cultures. These results suggest that HIV-1 isolates differ in
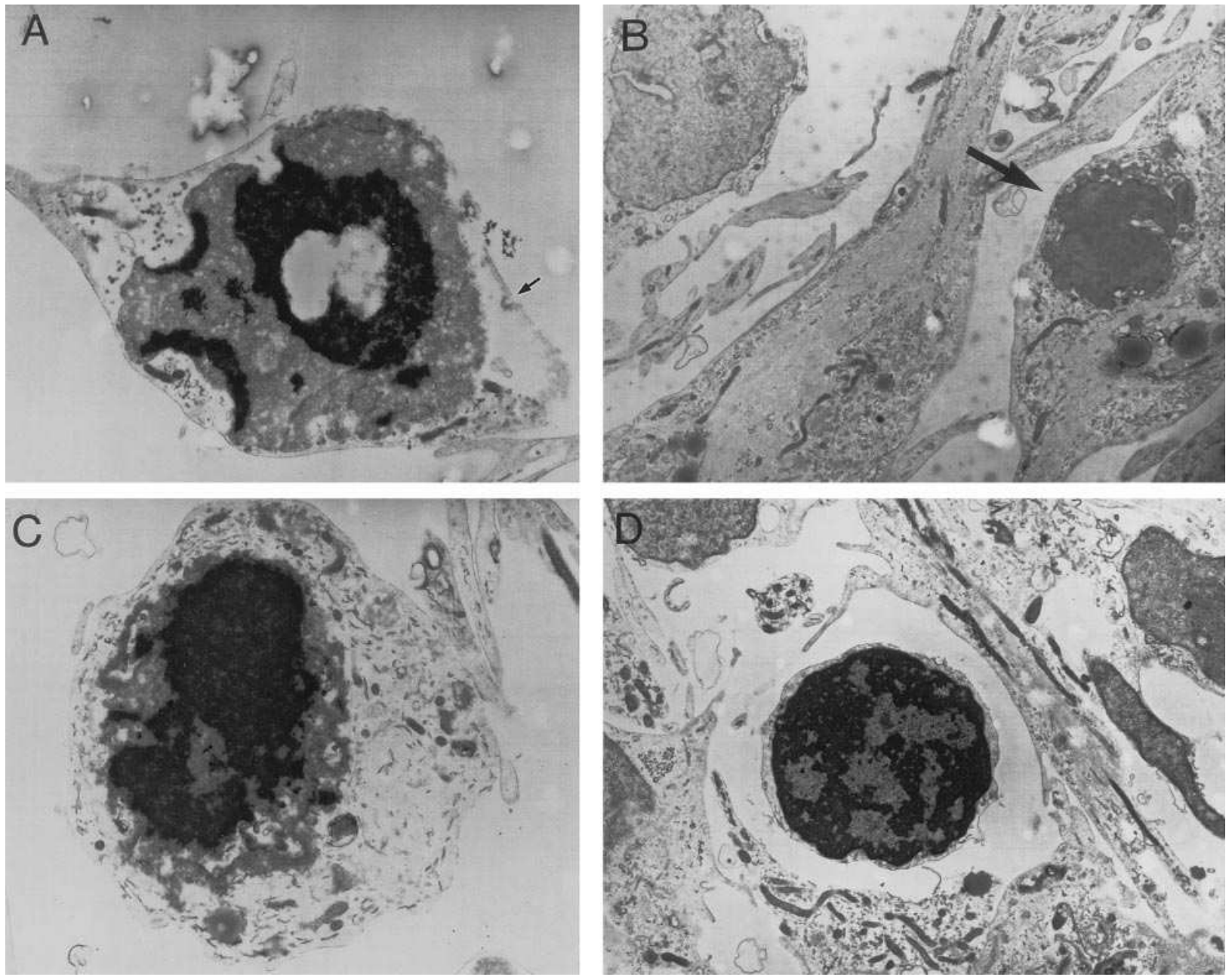

Figure 3. Electron microscopy of HIV-1-infected primary human fetal brain cultures. Nuclear abnormalities characteristic of apoptosis are shown in $A-D$. Cultures were fixed on day 28 after infection with HIV-1 89.6. ( $A$ ) Apoptotic neuron. The condensed chromatin forming crescents in apposition to the nuclear envelope is characteristic of the early stages of apoptosis. The large round nucleus occupying most of the perikaryon and the rounded membrane specialization resembling a synaptic cleft (arrow) are characteristic of neurons. $\times 10,000$. (B) Tunel-positive astrocyte (arrow) which demonstrates the condensed chromatin characteristic of apoptotic nuclei. TUNEL staining with DAB was performed prior to electron microscopy. Normal astrocytes are shown on the left. The irregular nuclear contour and abundant bundles of intermediate filaments in the cytoplasm are characteristic of astrocytes. $\times 4,800$. ( $C$ and $D$ ) Condensed chromatin in apoptotic nuclei is shown in degenerating cells. $C, \times 10,000 ; D, \times 5,800$. 


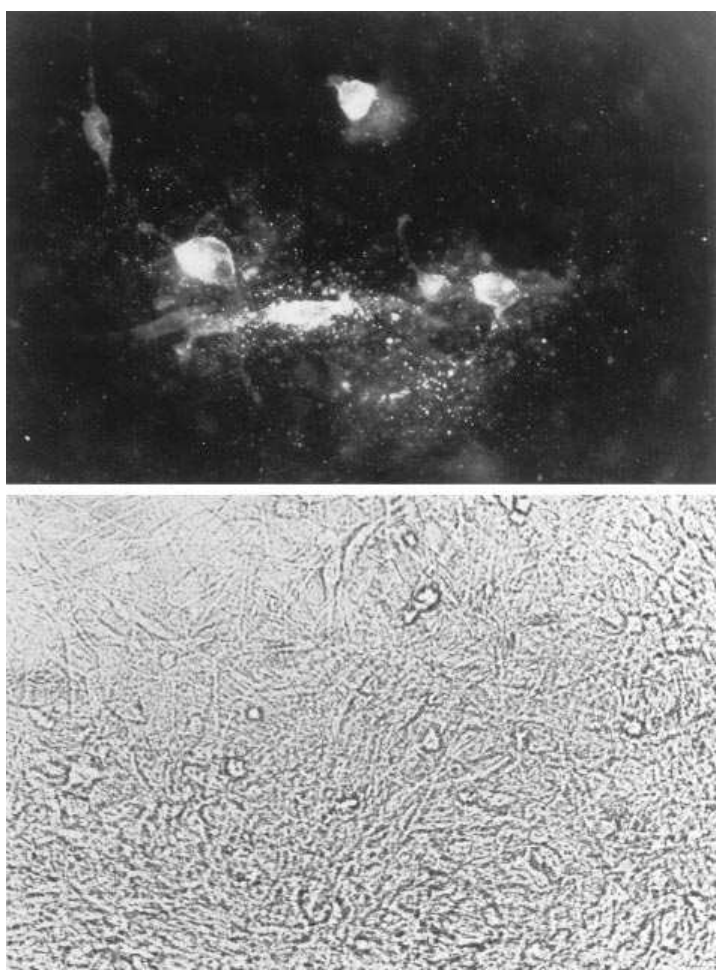

Figure 4. Combined TUNEL and HIV-1 p24 immunostaining of HIV-1-infected primary human fetal brain cultures. Cultures were fixed on day 30 after infection with HIV-1 89.6. Cluster of HIV-1infected microglia stained with anti-p24 (top) shows negative TUNEL staining (bottom). The same field is shown in both panels, but the planes of focus are different because the microglia layer (top) is on top of the astrocyte-neuron layer (bottom). $\times 800$.

their ability to induce apoptosis in primary brain cultures in vitro due to differences in the efficiency of virus replication or other determinants of viral pathogenicity.

The observation that apoptosis was not significantly induced in primary brain cultures infected with HIV-1 89.6 until 1-2 wk after the time of peak virus production suggests that apoptosis is likely to be induced by soluble factors acting at a distance rather than by direct infection. To further examine this possibility, combined TUNEL and immunofluorescence staining with anti-MAP-2 and anti-HIV-1 p24 was performed to determine whether the apoptotic cells were localized adjacent to HIV-1-infected macrophages and microglia. These experiments showed that clusters of p24-positive microglia were usually not localized adjacent to TUNEL-positive cells (Fig. 4). Similarly, most of the TUNEL-positive cells were not localized adjacent to p24-positive cells (not shown).

Detection of apoptosis in brain from AIDS patients. Combined TUNEL and immunohistochemical staining was performed to detect apoptosis in autopsy brain tissue from AIDS patients and non-AIDS control patients. In initial experiments, brain tissue from 13 AIDS patients, 1 HIV-seropositive symptom-free individual, and 17 non-AIDS control patients was examined. After excluding patients with histopathological evidence of anoxic/ischemic encephalopathy, necrosis, or postmortem autolysis, tissue from 10 AIDS patients, 1 HIV-seropositive individual, and 13 non-AIDS control patients was then used for further studies. The clinical and pathological characteristics of the patients are described in Table I. The non-AIDS control patients consisted of two groups: patients with normal brain $(n=6)$ and patients with Alzheimer's disease or senile plaques $(n=7)$. The mean age of the AIDS patients was 36 years (range, 27-48) and the mean age of the non-AIDS normal control patients was 39 years (range, 0-64). The mean age of the non-AIDS control patients with Alzheimer's disease or senile plaques was 78 years (range, 69-89). The mean postmortem intervals for the AIDS and non-AIDS control patients were similar (13.6 vs. $13.9 \mathrm{~h}$ ). Previous studies have shown that postmortem intervals up to $70 \mathrm{~h}$ do not appear to have a significant effect on detection of apoptosis in the brain by TUNEL staining (30-32).

TUNEL staining of autopsy brain tissue was performed to detect apoptosis in situ. Apoptotic cells were detected in cortex and basal ganglia from 10/11 AIDS patients, but were absent or rare in normal control patients (Table I; Fig. 5, $A$ and $B)$. To confirm that TUNEL staining specifically detected apoptotic cells, adjacent brain tissue sections were stained with propidium iodide or analyzed by electron microscopy to demonstrate apoptotic nuclear morphology. Propidium iodide staining showed chromatin condensation and nuclear fragmentation (Fig. $5 \mathrm{C}$ ), which was confirmed by electron microscopy (see Fig. 7). Apoptosis of cells with morphological characteristics of neurons, astrocytes, and endothelial cells was detected in $7 / 11,10 / 11$, and 10/11 AIDS patients, respectively, (Table I and Fig. 5, $D-F$ ), and was confirmed by combined TUNEL staining and immunostaining with the cell-specific markers anti-neurofilament, anti-GFAP, and anti-Factor VIII (Fig. 6). However, many TUNEL-positive cells were not double stained with these cell-specific markers, probably representing degenerating cells in the final stages of apoptosis or other cell types such as microglia or oligodendrocytes. The density of TUNEL-positive cells was non-uniform, and within a given patient there was variability in the number of apoptotic cells in different brain regions (Table I). TUNEL-positive neurons were detected more frequently in basal ganglia (4/5 sections) than in cerebral cortex (5/13 sections) (Table I). TUNEL-positive astrocytes were most frequently detected in the white matter, particularly in areas of reactive gliosis, but were also detected in basal ganglia and cerebral cortex (Table I and Fig. 5 and 6). Apoptosis of endothelial cells was detected in small and medium-sized blood vessels scattered throughout the gray and white matter (Table I and Figs. 5 and 6). Electron microscopy studies of brain tissue from two AIDS patients confirmed ultrastructural features characteristic of apoptosis in TUNELpositive endothelial cells (Fig. 7). Apoptotic cells were detected in 5/5 demented and 4/5 nondemented AIDS patients, but were more abundant in the demented patients. Apoptosis was detected in $7 / 7$ patients with histopathologic evidence of HIV-1 encephalitis and in 3/4 patients without HIV-1 encephalitis. In normal control patients, TUNEL staining was absent or limited to rare scattered astrocytes in the white matter (Table I). However, apoptotic neurons and astrocytes were frequently detected in 7/7 non-AIDS control patients with Alzheimer's disease or abundant senile plaques in the hippocampus and affected regions of cerebral cortex (Table I).

The in vitro experiments indicated that most of the TUNELpositive cells in HIV-1-infected primary brain cultures were not localized adjacent to HIV-1-infected cells. To determine whether this also occurs in vivo, combined TUNEL and HIV-1 Nef immunostaining was performed on autopsy brain tissue 


\begin{tabular}{|c|c|c|c|c|c|c|c|c|c|}
\hline \multirow[b]{2}{*}{ Patient } & \multirow{2}{*}{$\begin{array}{l}\text { Age } \\
\text { (yr) }\end{array}$} & \multirow{2}{*}{$\begin{array}{l}\text { PMI } \\
\text { (h) }\end{array}$} & \multirow[b]{2}{*}{ Diagnosis } & \multirow[b]{2}{*}{ Dementia } & \multirow[b]{2}{*}{ Neuropathology } & \multirow{2}{*}{$\begin{array}{c}\text { Brain } \\
\text { Region* }\end{array}$} & \multicolumn{3}{|c|}{ Apoptosis $^{\ddagger}$} \\
\hline & & & & & & & Neuron & Astrocyte & Endothelial \\
\hline 1 & 28 & 2 & AIDS & + & Severe HIVE & $\mathrm{BG}\left(3^{+}\right)$ & $1^{+}$ & $3^{+}$ & $2^{+}$ \\
\hline 2 & 47 & 17 & AIDS & NA & Severe HIVE & $\mathrm{CTX}(0)$ & $3^{+}$ & $1^{+}$ & $2^{+}$ \\
\hline \multirow[t]{2}{*}{3} & 33 & 21 & AIDS & + & Mild HIVE & $\operatorname{CTX}\left(2^{+}\right)$ & 0 & $2^{+}$ & $2^{+}$ \\
\hline & & & & & & & 0 & $2^{+}$ & $2^{+}$ \\
\hline 4 & 39 & 5 & AIDS & + & Severe HIVE & $\operatorname{CTX}\left(3^{+}\right)$ & $3^{+}$ & $3^{+}$ & $3^{+}$ \\
\hline \multirow[t]{3}{*}{5} & 35 & 11 & AIDS & + & Severe HIVE & $\mathrm{CTX}(0)$ & $2^{+}$ & $3^{+}$ & $3^{+}$ \\
\hline & & & & & & $\operatorname{CTX}\left(1^{+}\right)$ & $1^{+}$ & $1^{+}$ & $2^{+}$ \\
\hline & & & & & & $\mathrm{BG}\left(3^{+}\right)$ & $3^{+}$ & $2^{+}$ & $2^{+}$ \\
\hline \multirow[t]{3}{*}{6} & 27 & 8 & AIDS & - & Mild HIVE & $\operatorname{CTX}(0)$ & 0 & 0 & 0 \\
\hline & & & & & & $\operatorname{CTX}\left(1^{+}\right)$ & 0 & 0 & $2^{+}$ \\
\hline & & & & & & $\mathrm{BG}\left(1^{+}\right)$ & $1^{+}$ & $1^{+}$ & $1^{+}$ \\
\hline 7 & 31 & 19 & AIDS & + & Mild HIVE & $\operatorname{CTX}\left(1^{+}\right)$ & 0 & $1^{+}$ & $2^{+}$ \\
\hline 8 & 48 & 2 & AIDS & - & Normal & $\operatorname{CTX}(0)$ & 0 & 0 & 0 \\
\hline \multirow[t]{2}{*}{9} & 35 & 5 & AIDS & - & Normal & $\mathrm{BG}(0)$ & 0 & $1^{+}$ & 0 \\
\hline & & & & & & $\operatorname{CTX}(0)$ & 0 & $1^{+}$ & $1^{+}$ \\
\hline \multirow[t]{2}{*}{10} & 34 & 6 & AIDS & - & Normal & $\mathrm{BG}(0)$ & $3^{+}$ & $1^{+}$ & $2^{+}$ \\
\hline & & & & & & $\mathrm{CTX}(0)$ & 0 & $3^{+}$ & $2^{+}$ \\
\hline 11 & 29 & 54 & HIV+,IVD & - & Normal & $\operatorname{CTX}(0)$ & $2^{+}$ & $3^{+}$ & $2^{+}$ \\
\hline 12 & 29 & 9 & Normal & - & Normal & $\operatorname{CTX}(0)$ & 0 & 0 & 0 \\
\hline 13 & 20 & 15 & Normal & - & Normal & $\mathrm{CTX}(0)$ & 0 & $1^{+}$ & 0 \\
\hline 14 & 64 & 16 & Normal & - & Normal & $\operatorname{CTX}(0)$ & 0 & $1^{+}$ & 0 \\
\hline \multirow[t]{2}{*}{15} & 37 & 12 & Breast CA & - & Normal & $\mathrm{CTX}(0)$ & 0 & $2^{+}$ & 0 \\
\hline & & & & & & $\mathrm{CTX}(0)$ & 0 & 0 & 0 \\
\hline 16 & 44 & 6 & Lymphoma & - & Normal & $\mathrm{BG}(0)$ & 0 & $1^{+}$ & 0 \\
\hline \multirow[t]{2}{*}{17} & 0 & 35 & Stillborn & - & Normal & $\mathrm{BS}(0)$ & 0 & 0 & 0 \\
\hline & & & Infant & & & & & & \\
\hline 18 & 70 & 16 & $\mathrm{PE}$ & - & Senile plaques & $\operatorname{CTX}\left(1^{+}\right)$ & $3^{+}$ & $3^{+}$ & 0 \\
\hline 19 & 83 & 18 & MI & - & $\begin{array}{l}\text { Senile plaques, } \\
\text { NFT }\end{array}$ & $\operatorname{CTX}\left(1^{+}\right)$ & $3^{+}$ & $3^{+}$ & 0 \\
\hline 20 & 78 & 5 & MI & - & Severe AD & $\operatorname{CTX}\left(3^{+}\right)$ & $3^{+}$ & $3^{+}$ & 0 \\
\hline 21 & 69 & NA & $\mathrm{AD}$ & + & Severe AD & $\operatorname{CTX}\left(3^{+}\right)$ & $3^{+}$ & $3^{+}$ & 0 \\
\hline 22 & 73 & 13 & $\mathrm{AD}$ & + & Severe AD & $\operatorname{CTX}\left(3^{+}\right)$ & $3^{+}$ & $3^{+}$ & 0 \\
\hline 23 & 82 & 7 & $\mathrm{AD}$ & + & Severe AD & $\operatorname{CTX}\left(3^{+}\right)$ & $3^{+}$ & $3^{+}$ & 0 \\
\hline 24 & 89 & 15 & $\mathrm{AD}$ & + & Severe AD & $\operatorname{CTX}\left(3^{+}\right)$ & $3^{+}$ & $3^{+}$ & 0 \\
\hline
\end{tabular}

*Tissues were obtained at autopsy. Shown in parentheses is grading of HIVE (patients 1-11), senile plaques (patients 18 and 19), or AD (patients 2024) as 0 (negative), $1^{+}$(mild), $2^{+}$(moderate), or $3^{+}$(severe). ${ }^{\ddagger}$ Apoptosis was detected by TUNEL staining of formalin-fixed paraffin sections. TUNEL staining of each cell type was graded as 0 (absent) $1^{+}$(rare), $2^{+}\left(<20\right.$ cells per section), and $3^{+}(>20$ cells per section). PMI, postmortem interval; $H I V E$, HIV-1 encephalitis; $B G$, basal ganglia; $N A$, not available; $C T X$, cerebral cortex; $H I V+$, asymptomatic HIV-1-seropositive; $I V D$, intravenous drug use; $C A$, carcinoma; $B S$, brainstem; $P E$, pulmonary embolus; $N F T$, neurofibrillary tangles; $M I$, myocardial infarction; $A D$, Alzheimer's disease.

from AIDS patients. HIV-1 Nef was detected in microglial nodules, multinucleated giant cells, and perivascular macrophages in 6/10 AIDS patient brain tissue sections examined. There was no significant association between the localization of HIV-1 Nef-positive cells and TUNEL-positive cells (Fig. 8). The HIV-1 Nef-positive cells were usually not localized adjacent to TUNEL-positive cells (Fig. $8 A$ ). Similarly, most of the TUNEL-positive cells were not localized adjacent to HIV-1 Nef-positive cells or to histopathologic lesions characteristic of productive HIV-1 infection (Fig. 8 B). However, a small fraction of the TUNEL-positive cells were occasionally detected adjacent to foci of productive HIV-1 infection. Similar results were obtained when TUNEL staining was combined with antiHIV-1 p24 immunostaining (not shown).

\section{Discussion}

In this study, we demonstrate that apoptosis is induced by HIV-1 infection of the CNS both in vitro and in vivo. This study is the first demonstration that HIV-1 infection of primary human brain cultures induces apoptosis of neurons and astrocytes in vitro. We also demonstrate apoptosis of neurons and astrocytes in brain tissue from AIDS patients, consistent with previous studies (30-32). Additionally, our in vivo studies show that endothelial cell apoptosis occurs in small and medium-sized blood vessels in the brain of AIDS patients, an abnormality which might disrupt the blood-brain-barrier $(16,17$, 41). In contrast to previous studies $(30,31)$, TUNEL-positive cells resembling microglia were infrequently detected in only 

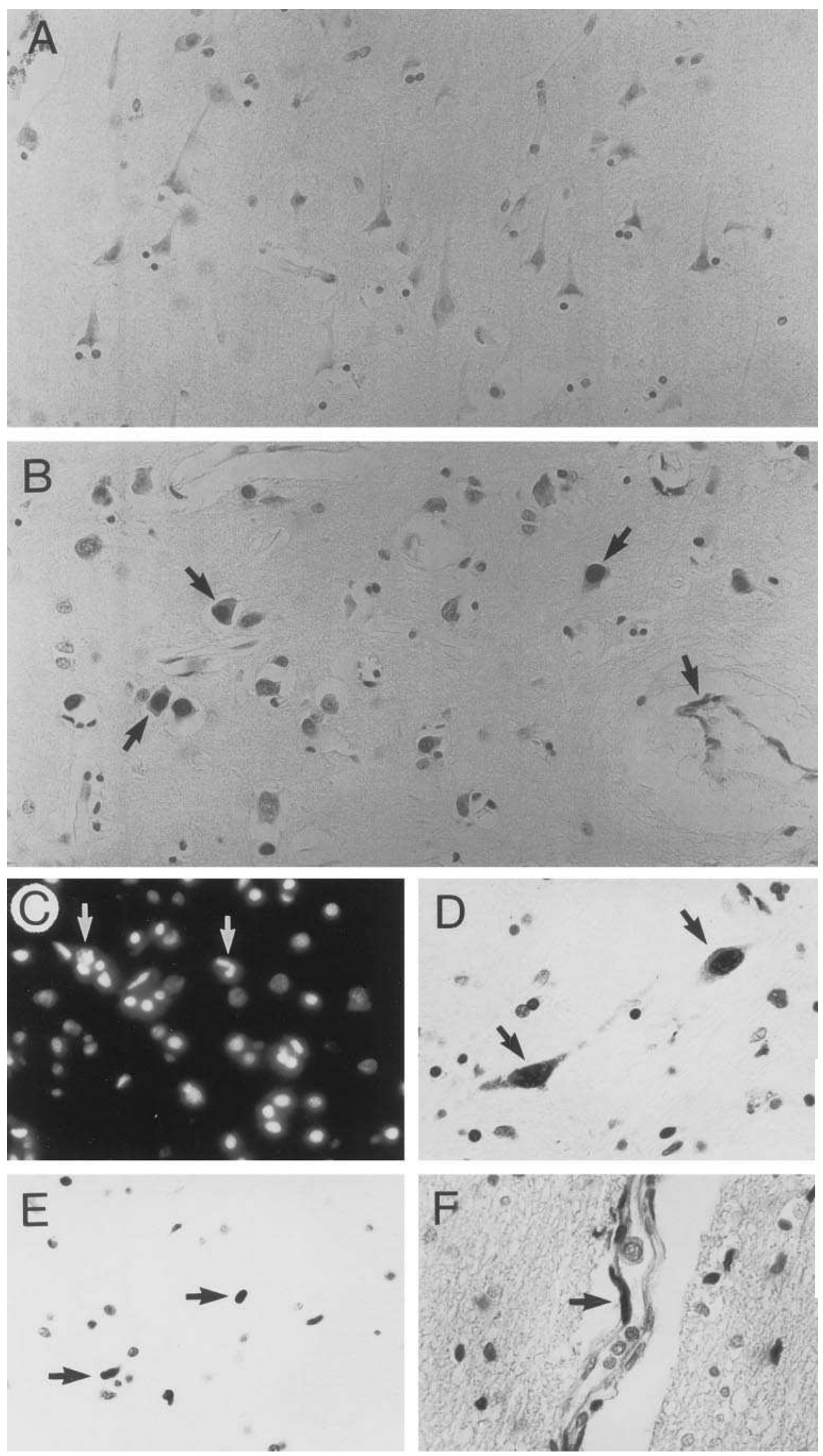

Figure 5. Apoptosis in autopsy brain tissue from AIDS patients. ( $A$ and $B$ ) TUNEL staining of brain from a non-AIDS normal control patient $(A)$ and AIDS patient with dementia $(B)$. Note TUNEL-positive cells in $B$ (arrows). $\times 550$. (C) Propidium iodide staining of AIDS patient brain tissue demonstrates cells with apoptotic nuclear morphology (arrows). $\times 400$. $(D, E$, and $F)$ TUNEL-positive neurons $(D)$, astrocytes $(E)$, and endothelial cells $(F)$ in gray $(D)$ and white $(E$ and $F)$ matter (arrows). Note that $D$ and $F$ also show TUNEL-positive glial cells. $\times 800$ 


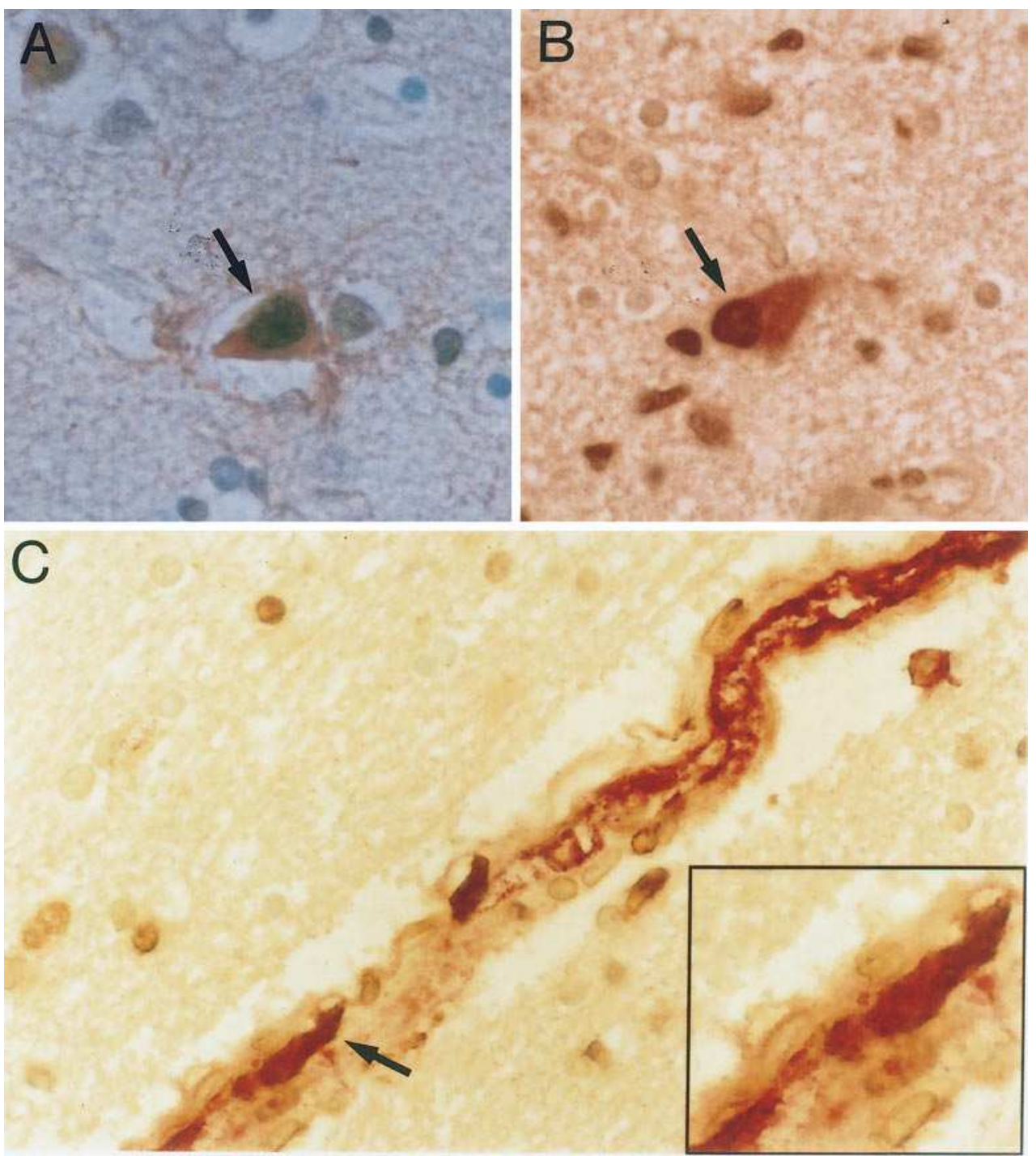

Figure 6. Apoptosis of neurons, astrocytes, and endothelial cells in brain from AIDS patients demonstrated by double staining with cell-specific markers. Combined TUNEL staining and immunostaining with the cell-specific markers anti-neurofilament $(A)$, anti-GFAP $(B)$, and antiFactor VIII $(C)$ confirms apoptosis of neurons, astrocytes, and endothelial cells, respectively (arrows). Insert in $C$ shows a TUNEL-positive Factor VIIIpositive endothelial cell (arrow) at higher magnification. $A-C$, $\times 1440$; inset, $\times 2800$.
2/11 AIDS patients (B. Shi, U. DeGirolami, and D. Gabuzda, unpublished data). These results suggest that apoptosis of neurons, astrocytes, and endothelial cells is a likely mechanism of CNS injury leading to cognitive dysfunction in AIDS patients.

Our studies provide in vitro and in vivo evidence that most of the apoptosis induced by HIV-1 infection of the CNS does not occur adjacent to HIV-1-infected macrophages and microglia. Furthermore, apoptosis is not significantly induced by HIV-1 infection of primary brain cultures until one to two weeks after the time of peak virus production. Together, these results suggest that the apoptotic stimuli are likely to be soluble factors acting at a distance rather than direct viral infection. The finding that endothelial cell apoptosis occurs in the brain of most AIDS patients raises the possibility that some of these factors may be blood-derived. Several potential candidates for the apoptotic stimuli in the brain of AIDS patients have been suggested by previous studies. A soluble form of the HIV-1 gp120 protein is neurotoxic in vitro (42) and has been shown to induce neuronal apoptosis (43). The HIV-1 Tat protein, which is present in AIDS patient serum in a soluble form, is another potential apoptotic stimulus with known neurotoxic effects $(27,44)$. Another potential candidate is TNF- $\alpha$, which is elevated in the serum, CSF, and brain of AIDS patients, par- ticularly since elevated TNF- $\alpha$ levels have been shown to correlate with clinical dementia $(4,28)$. Further studies are required to determine whether one or more of these factors, or other unknown factors, cause apoptosis and neuronal loss in the brain of AIDS patients. It is possible that some of these factors may not be unique to HIV-1 infection. For example, previous studies have shown that Sindbis virus induces neuronal apoptosis in the brain of infected mice (45).

Our results suggest that endothelial cell apoptosis may contribute to CNS injury in AIDS. Endothelial cell apoptosis in vivo has been demonstrated to occur in acute lung injury, the fibrotic skin diseases scleroderma and systemic sclerosis, or as a complication of ionizing radiation (46-48), but to our knowledge has not been shown in AIDS or other diseases. Previous studies have demonstrated microvascular abnormalities in the CNS and increased blood-brain barrier permeability in AIDS patients $(16,17,41)$. Our findings suggest that endothelial cell apoptosis may contribute to these microvascular pathologies. Further studies will determine whether endothelial cell apoptosis results in significant disruption of the blood-brain barrier. Further studies are also required to determine whether apoptosis of endothelial cells in the CNS of AIDS patients is induced by soluble factors derived from the blood or by direct 


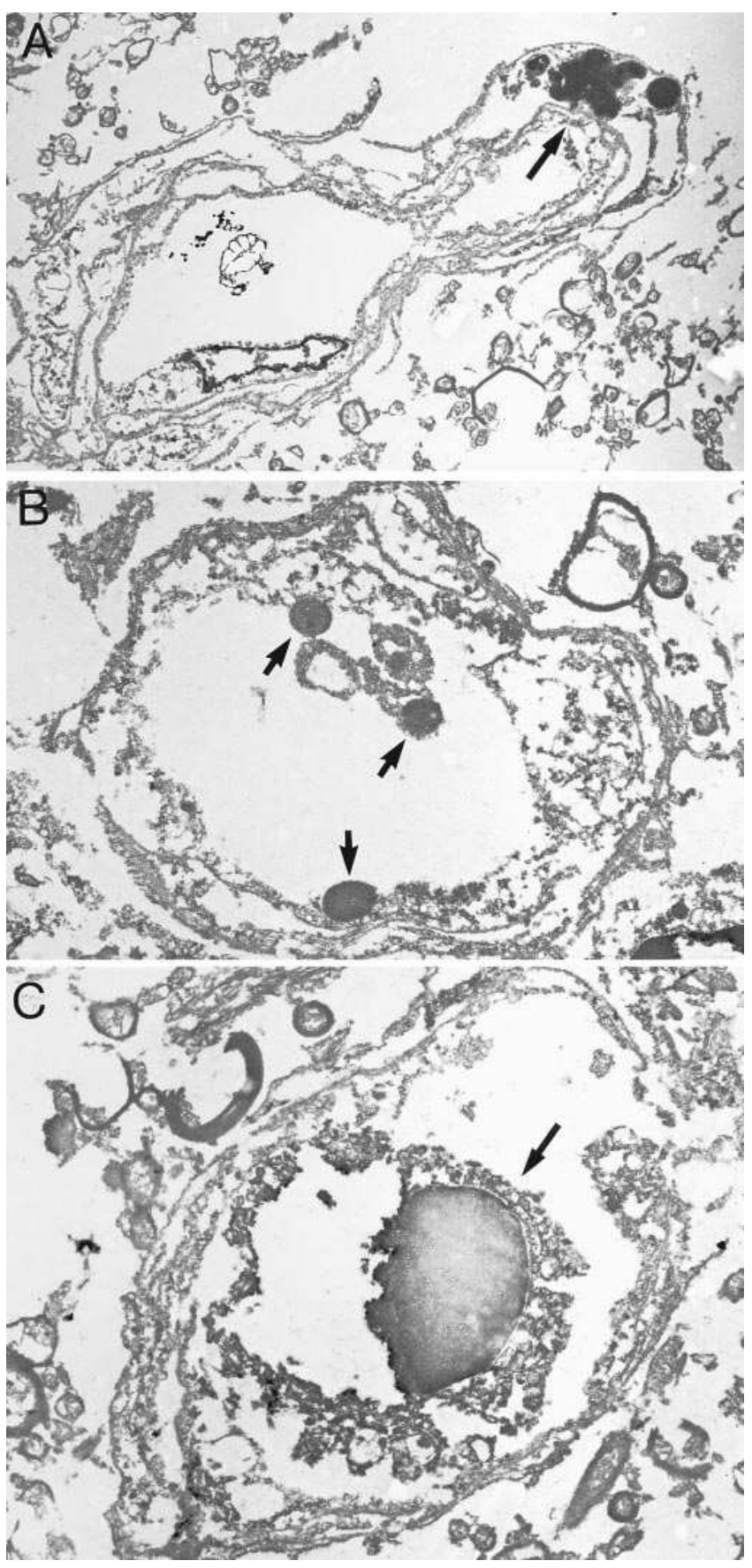

Figure 7. Electron microscopy of brain tissue from AIDS patients. Ultrastructural features characteristic of apoptosis in endothelial cells. Deparaffinized sections of autopsy brain tissue from two patients (patients 1 and 4, Table I) were stained by the TUNEL method, fixed, postfixed, and embedded as described in the Methods. $(A)$ Apoptotic microvascular cell which demonstrates nuclear fragmentation into apoptotic bodies (arrow). $\times 2,600$. (B) Apoptotic bodies (arrows) apposed to the intimal surface of a small blood vessel. $\times 5,600$. (C) Microvascular endothelial cell which demonstrates chromatin condensation characteristic of apoptotic nuclear morphology and degenerating cytoplasm. $\times 5,000$. Note that the apoptotic nuclei and apoptotic bodies shown in $A-C$ are stained with DAB, indicating that they are TUNEL-positive.

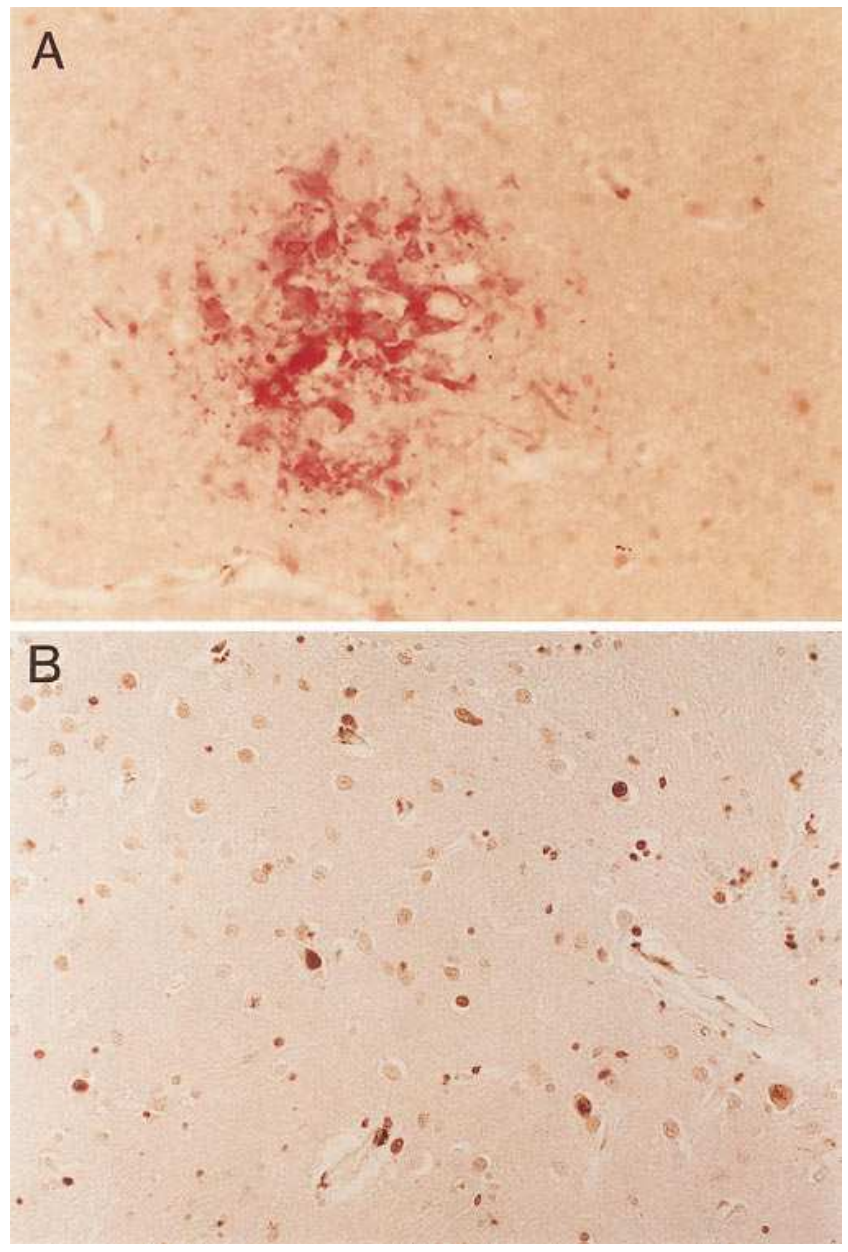

Figure 8. Combined TUNEL and HIV-1 immunostaining of brain tissue from AIDS patients. Combined TUNEL staining and immunostaining with anti-HIV-1 Nef is shown in $A$ and $B$. (A) Microglial nodule which demonstrates HIV-1 Nef immunostaining. HIV-1 Nefpositive microglia and multinucleated giant cells are shown. Note the absence of significant TUNEL staining. (B) TUNEL-positive cells which are not associated with HIV-1 Nef immunostaining. $\times 260$.

HIV-1 infection at low levels which were not detected by the methods used in this study.

One puzzling aspect of HIV-1 dementia is the frequent lack of correlation between the clinical deficit and the severity of neuropathology. Previous studies have documented neuronal loss in both demented and nondemented AIDS patients (19, 20). As many as $50 \%$ of AIDS patients with dementia do not have histopathologic evidence of HIV-1 encephalitis, particularly patients with milder symptoms $(4,7)$. Moreover, some patients with HIV-1 encephalitis do not have clinical dementia $(4,7,18)$. In this study, apoptosis was detected in the brain of 7/7 patients with HIV-1 encephalitis, with apoptotic cells more frequent in the most severely affected brain regions. Apoptotic cells were also detected in the brain of $3 / 4$ patients without HIV-1 encephalitis, but with lower frequency. Similarly, apoptotic cells were more frequent in the brain of demented than nondemented AIDS patients, but were detected in both. Thus, apoptosis may account for the neuronal loss and cognitive dysfunction which has been documented in some patients with minimal or no detectable neuropathology, since apoptosis is 
not associated with inflammatory or necrotic lesions. These results and those of others (49) raise the possibility that apoptosis may be an early cause of neuronal loss in some AIDS patients prior to the onset of overt cognitive impairment.

The cell culture model for HIV-1-induced neuronal apoptosis described in this study is the first to directly demonstrate neuronal apoptosis induced by HIV-1 infection in vitro. Potential applications of this in vitro model include studies on molecular mechanisms of HIV-1-induced CNS injury. Our studies suggest that macrophagetropic HIV-1 isolates may differ in their ability to induce neuronal apoptosis in vitro. Whether this phenotypic difference merely reflects the efficiency of virus replication in the CNS or results from other determinants of viral pathogenicity remains to be determined. Previous studies suggest that macrophage tropism is necessary for HIV-1 infection of the CNS, but is not sufficient to cause dementia (50). Thus, this cell culture model can be used to experimentally address important questions such as the biological properties of particular HIV-1 strains which cause clinical dementia and the identification of viral or host factors which mediate CNS injury. This cell culture model may also provide a new opportunity to test potential neuroprotective agents.

\section{Acknowledgments}

We acknowledge Dr. Bruce Yankner for helpful discussions and providing primary brain cultures and Dr. Yuhui Xu for performing electron microscopy studies. HIV-1 89.6 was obtained through the AIDS Research and Reference Reagent Program, NIAID, NIH (donated by Dr. Ronald Collman). HIV-1 YU-2.C was provided by Dr. Beatrice Hahn, Dr. George Shaw, and Dr. Sajal Ghosh.

This work was supported by Pediatric AmFAR grant 50565-18PG, National Institutes of Health grant NS35734, Center for AIDS Research (CFAR) Core grant (AI28691), a Claudia A. Barr Investigator Award, the William Randolph Hearst Fund, the G. Harold and Leila Mathers Charitable Foundation, and the Dana-Farber Friends 10. We acknowledge the CFAR and Center for Cancer Research (AO6514) grants for supporting necessary core facilities.

\section{References}

1. Brew, B.J., M. Rosenblum, K. Cronin, and R.W. Price. 1995. AIDS dementia complex and HIV-1 brain infection: clinical-virological correlations. Ann. Neurol. 38:563-570.

2. Epstein, L.G., and H.E. Gendelman. 1993. Human immunodeficiency virus type 1 infection of the nervous system: pathogenetic mechanisms $\mathrm{Ann}$. Neurol. 33:429-430.

3. Gabuzda, D.H., and M.S. Hirsch. 1987. Neurologic manifestations of infection with human immunodeficiency virus. Ann. Intern. Med. 107:383-391.

4. Glass, J.D., S.L. Wesselingh, O.A. Selnes, and J.C. McArthur. 1993. Clinical-neuropathologic correlation in HIV-associated dementia. Neurology. 43: 2230-2237.

5. Price, R.W. 1988. The brain in AIDS: central nervous system HIV-1 infection and AIDS dementia complex. Science (Wash. DC). 239:586-591.

6. Gabuzda, D.H., D.D. Ho, M.S. de la Monte, T.R. Rota, and R.A. Sobel. 1986. Immunohistochemical identification of HTLV-III antigen in brains of patients with AIDS. Ann. Neurol. 20:289-295.

7. Glass, J.D., H. Fedor, S.L. Wesselingh, and J.C. McArthur. 1995. Immunocytochemical quantitation of human immunodeficiency virus in the brain: correlations with dementia. Ann. Neurol. 38:755-762.

8. Ward, J.M., T.J. O'Leary, G.B. Baskin, R. Benveniste, C.A. Harris, P.L. Nara, and R.H. Rhodes. 1987. Immunohistochemical localization of human and simian immunodeficiency viral antigens in fixed tissue sections. Am. J. Pathol. 127:199-205.

9. Wiley, C.A., R.D. Schrier, J.A. Nelson, P.W. Lampert, and M.B.A. Oldstone. 1986. Cellular localization of human immunodeficiency virus within the brains of acquired immunodeficiency patients. Proc. Natl. Acad. Sci. USA 83: 7089-7093.

10. Moses, A.L., F.E. Bloom, C.D. Pauza, and J.A. Nelson. 1993. Human immunodeficiency virus infection of human brain capillary endothelial cells occurs via a CD4/galactosylceramide-independent mechanism. Proc. Natl. Acad. Sci. USA. 90:10474-10478.

11. Ranki, A., M. Nyberg, V. Ovod, M. Haltia, I. Elovaara, R. Raininko, H. Haapasalo, and K. Krohn. 1995. Abundant expression of HIV Nef and Rev proteins in brain astrocytes in vivo is associated with dementia. AIDS. 9:1001-1008.

12. Saito, Y., L.R. Sharer, L.G. Epstein, J. Michaels, M. Mintz, M. Louder, K. Golding, T.A. Cvetkovich, and B.M. Blumberg. 1994. Overexpression of nef as a marker for restricted HIV-1 infection of astrocytes in postmortem pediatric central nervous tissues. Neurology. 44:474-481.

13. Tornatore, C., R. Chandra, J.R. Berger, and E.O. Major. 1991. HIV-1 infection of subcortical astrocytes in the pediatric central nervous system. Neurology. 44:481-487.

14. Kure, K., J.F. Llena, W.D. Lyman, R. Soeiro, K.M. Weidenheim, A. Hirano, and D.W. Dickson. 1991. Human immunodeficiency virus-1 infection of the nervous system: an autopsy study of 268 adult, pediatric, and fetal brains. Hum. Pathol. 22:700-710.

15. Navia, B., E.S. Cho, C.K. Petito, and R.W. Price. 1986. The AIDS dementia complex. II. Neuropathology. Ann Neurol. 19:525-535.

16. Power, C., P-A. Kong, T.O. Crawford, S. Wesselingh, J.D. Glass, J.C. McArthur, and B.D. Trapp. 1993. Cerebral white matter changes in acquired immunodeficiency syndrome dementia: alterations of the blood-brain barrier. Ann. Neurol. 34:339-350.

17. Smith, T.W., U. DeGirolami, D. Heñin, F. Bolgert, and J.-J. Hauw. 1990. Human immunodeficiency virus (HIV) leukoencephalopathy and the microcirculation. J. Neuropathol. Exp. Neurol. 49:357-370.

18. Wiley, C.A., and C. Achim. 1994. Human immunodeficiency virus encephalitis is the pathological correlate of dementia in acquired immunodeficiency syndrome. Ann. Neurol. 36:673-676.

19. Everall, I.P., J.D. Glass, J. McArthur, E. Spargo, and L. Lantos. 1994 Neuronal density in the superior frontal and temporal gyri does not correlate with the degree of human immunodeficiency virus-associated dementia. Acta Neuropathol. 88:538-544.

20. Ketzler, S., S. Weis, H. Haug, and H. Budka. 1990. Loss of neurons in the frontal cortex in AIDS brains. Acta Neuropathol. 80:92-94.

21. Masliah, E., C.L. Achim, N. Ge, R. DeTeresa, R.D. Terry, and C.A. Wiley. 1992. Spectrum of human immunodeficiency virus-associated neocortical damage. Ann. Neurol. 32:321-329.

22. Wiley, C.A., E. Masliah, M. Morey, C. Lemere, R. DeTeresa, M. Grafe, L. Hansen, and R. Terry. 1991. Neocortical damage during HIV infection. Ann. Neurol. 29:651-657.

23. Sinclair, E., F. Gray, A. Ciardi, and F. Scaravilli. 1994. Immunohistochemical changes and PCR detection of HIV provirus DNA in brains of asymptomatic HIV-positive patients. J. Neuropath. Exp. Neurol. 53:43-50.

24. Pulliam, L., B.G. Herndier, N.M. Tang, and M.S. McGrath. 1991. Human immunodeficiency virus-infected macrophages produce soluble factors that cause histological and neurochemical alterations in cultured human brains. J. Clin. Invest. 87:503-512.

25. Gelbard, H.A., H.S. Nottet, S. Swindells, M. Jett, K.A. Dzenko, P. Genis, R. White, L. Wang, Y. Choi, D. Zhang et al. 1994. Platelet-activating factor: a candidate human immunodeficiency virus type 1-induced neurotoxin. J. Virol. 68:4628-4635.

26. Genis, P., M. Jett, E.W. Bernton, T. Boyle, H.A. Gelbard, K. Dzenki, R.W. Keane, L. Resnick, Y. Mizrachi, D.J. Volsky et al. 1992. Cytokines and arachidonic metabolites produced during human immunodeficiency virus (HIV)-infected macrophage-astroglia interactions: implications for the neuropathogenesis of HIV disease. J. Exp. Med. 176:1703-1718.

27. Magnuson, D.S.K., B.E. Knudsen, J.D. Geiger, R.M. Brownstone, and A. Nath. 1995. Human immunodeficiency virus type 1 Tat activates non- $N$ methyl-D-asparate excitatory amino acid receptors and causes neurotoxicity. Ann. Neurol. 37:373-380.

28. Wesselingh, S.L., C. Power, J.D. Glass, W.R. Tyor, J.C. McArthur, J.M. Farber, J.W. Griffin, and D.E. Griffin. 1993. Intracerebral cytokine messenger RNA expression in AIDS dementia. Ann. Neurol. 33:576-582.

29. Oyaizu, N., and S. Pahwa. 1995. Role of apoptosis in HIV disease pathogenesis. J. Clin. Immunol. 15:217-231.

30. Adie-Biassette, H., Y. Levy, M. Colombel, F. Poron, S. Natchev, C. Keohane, and F. Gray. 1995. Neuronal apoptosis in HIV infection in adults. Neuropathol. Appl. Neurobiol. 21:218-227.

31. Gelbard, H.A., H.J. James, L.R. Sharer, S.W. Perry, Y. Saito, A.M. Kazee, B.M. Blumberg, and L.G. Epstein. 1995. Apoptotic neurons in brains from paediatric patients with HIV-1 encephalitis and progressive encephalopathy. Neuropathol. Appl. Neurobiol. 21:208-217.

32. Petito, C.K., and B. Roberts. 1995. Evidence of apoptotic cell death in HIV encephalitis. Am. J. Pathol. 146:1121-1130.

33. Zazopoulos, E., and W. Haseltine. 1993. Effect of nef alleles on replication of human immunodeficiency virus type 1. Virology. 194:20-27.

34. Collman, R., J.W. Balliet, S.A. Gregory, H. Friedman, D.L. Kolson, N. Nathanson, and A. Srinivasan. 1992. An infectious molecular clone of an unusual macrophage-tropic and highly cytopathic stain of human immunodeficiency virus type 1.J. Virol. 66:7517-7521.

35. Li, Y., H. Hui, C.J. Burgess, R.W. Price, P.M. Sharp, B.H. Hahn, and 
G.M. Shaw. 1992. Complete nucleotide sequence, genome organization, and biological properties of human immunodeficiency virus type 1 in vivo: evidence for limited defectiveness and complementation. J. Virol. 66:6587-6600.

36. Busciglio, J., J. Yeh, and B.A. Yankner. 1993. $\beta$-amyloid neurotoxicity in human cortical culture is not mediated by excitotoxins J. Neurochem. 61: $1565-1668$.

37. Rho, H.M., B. Poiesz, W. Ruscetti, and R. C. Gallo. 1981. Characterization of the reverse transcriptase from a new retrovirus (HTLV) produced by a human cutaneous T-cell lymphoma cell line. Virology. 112:355-360.

38. Gavrieli, Y., Y. Sherman, and S.A. Ben-Sasson. 1992. Detection of programmed cell death in vitro via specific labeling of nuclear DNA fragmentation. J. Cell Biol. 119:493-501.

39. Lee, S.C., W. Liu, Y. Kress, W.D. Lyman, and D.W. Dickson. 1993. Productive infection of human fetal microglia by HIV-1. Am. J. Pathol. 143:10321039.

40. Sharpless, N., D. Gilbert, B. Vandercam, J.M. Zhou, E. Verdin, G. Ronnett, E. Friedman, and M. Dubois-Dalcq. 1992. The restricted nature of HIV-1 tropism for cultured neural cells. Virology. 191:813-825.

41. Petito, C.K., and K.S. Cash. 1992. Blood-brain barrier abnormalities in the acquired immunodeficiency syndrome: immunohistochemical localization of serum proteins in postmortem brain. Ann. Neurol. 32:658-666.

42. Dreyer, E.B., P.K. Kaiser, J.T. Offerman, and S.A. Lipton. 1990. HIV-1 coat protein neurotoxicity prevented by calcium channel antagonists. Science (Wash. DC). 248:364-367.

43. Müller, W.E.G., H.C. Schröder, H. Ushijima, J. Dapper, and J. Ber- mann. 1992. gp120 of HIV-1 induces apoptosis in rat cortical cell cultures: prevention by memantine. Eur. J. Pharmacol. 226:209-214.

44. Li, C.J., D.J. Friedman, C. Wang, V. Metelev, and A.B. Pardee. 1995. Induction of apoptosis in uninfected T lymphocytes by HIV-1 Tat protein. Science (Wash. DC). 268:429-431.

45. Lewis, J., S.L. Wesselingh, D.E. Griffin, and J.M. Hardwick. 1996. Alphavirus-induced apoptosis in mouse brains correlates with neurovirulence. $J$. Virol. 70:1828-1835.

46. Polunovsky, V.A., B. Chen, C. Henke, D. Snover, C. Wendt, D.H. Ingbar, and P.B. Bitterman. 1993. Role of mesenchymal cell death in lung remodeling after injury. J. Clin. Invest. 92:388-397.

47. Fuks, Z., R.S. Persaud, A Alfieri, M. McLoughlin, D. Ehleiter, J.L. Schwartz, A.P. Seddon, C. Cordon-Cardo, and A. Haimovitz-Friedman. 1994. Basic fibroblast growth factor protects endothelial cells against radiation-induced programmed cell death in vitro and in vivo. Cancer Research. 54:2582-2590.

48. Sgonc, R., M.S. Gruschwitz, H. Dietrich, H. Recheis, M.E. Gershwin, and G. Wick. 1996. Endothelial cell apoptosis is a primary pathogenetic event underlying skin lesions in avian and human scleroderma. J. Clin. Invest. 98:785792.

49. An, S.F., F. Gray, and F. Scaravilli, F. 1995. Programmed cell death in brains of HIV-1-positive pre-AIDS patients. Lancet. 346:911-912.

50. Power, C., J.C. McArthur, R.T. Johnson, D.E. Griffin, J.D. Glass, S. Perryman, and B. Chesebro. 1994. Demented and nondemented patients with AIDS differ in brain derived human immunodeficiency virus type 1 envelope sequences. J. Virol. 68:4643-4649. 